\title{
Physical Education Curriculum Integral Ware Model Analysis based on Taekwondo
}

\author{
TingTing Wei \\ (Northwest A\&F University, Yangling, Shaanxi 712100, China)
}

\begin{abstract}
Keywords: Taekwondo; Physical education curriculum; Integral ware model
\end{abstract}
\begin{abstract}
With the improvement of computer technology, computers have found wide applications in many fields. The references of computers are becoming more common in physical education teaching. Complete physical education movement decomposition through the combination way of images, audio and video completes multi-angle teaching with comprehensive analysis and interpretation. It is conducive to a better students' understanding and contributes to the improvement of teaching efficiency and quality. The traditional CAI course-ware has poor flexibility, which cannot meet the needs of today's teaching. Integral ware combines teaching materials and expression. Teachers and students can get a lot of knowledge information material. This paper takes the establishment of physical education curriculum integral ware as a starting point, with the comparison with traditional course-ware, and analyzes the superiority and application value of integral ware in physical education course by taking taekwondo- one physical education curriculum- as an example.
\end{abstract}

At present, the combination way of education with computer and network technology is becoming more common and gradually gets the attention of teachers and students. Teaching software occupies the important position in education and the demand for software is constantly growing with higher demand for its quality. Software with stronger commercial usages is very difficult to satisfy teachers. Traditional way of teaching usually completes the teaching work according to teaching material content and teaching tasks, and now teaching pays more attention to students' interests, construction of teaching environment and learning atmosphere so as to fully mobilize students' study enthusiasm. CAI course-ware is often used in teaching. Its characteristics include beginning and ending, a system and all linked together, that is to say, in the process of teaching, a lack of any one of these links cannot work. Although CAI course-ware has these advantages, it has its drawbacks. Because of its operation must be from the beginning to the end, there can be no other changes among them, which solidifies the connection of knowledge and restricts the cultivation of student's way of thinking. Teaching also presents a large mechanization [1]. Therefore, teaching course-ware has the characteristics of flexible, adjustable and similar characteristics, and it can make corresponding adjustments according to the external environment, teaching content, students' practical acceptance ability, teaching schedule, and teachers' personality to better be applied to teaching situations.

\section{AN OVERVIEW ABOUT CAI, COURSE-WARE AND INTEGRAL WARE}

A. The concept introduction of CAI, course-ware, and integral ware

CAI means computer assisted instruction, which consists of computer hardware, system software and course software. System software mainly refers to operating system, language processing software, tools software and writing system. Tool software, such as word processing tools, graphics, etc., is in order to complete the development of CAI course-ware. Writing system is a software exempting teachers from learning programming language, such as PPT, etc.

Course-ware is the multimedia information integrated with text and images by teachers or a program design personnel by using computer according to specific needs of teaching. In combination with the teaching content, make software for learning with human-computer interaction operation [2]. Because it contains a variety of multimedia information, generally it is 
called "CAI course-ware" and its characteristics are as follows: first, course-ware and teaching contents are closely linked and is suitable for a particular knowledge or under specific teaching environment; Second, course-ware and teaching material are completely consistent and are arranged orderly according to textbook chapters and knowledge points; Third, it has immutable characteristics after the completion of course-ware making: high stability, specificity and sealing ability, which has a very big restriction effect on its application in teaching.

Integral ware refers that teachers and students make combined use of multimedia teaching information resource teaching software system according to the practical teaching and learning situation through resource integration. Integral ware library and integral ware combination platform are two important parts of integral ware. Integral ware library is the most basic teaching material and material library, which includes multimedia library and micro teaching unit library; multimedia library contains information such as voice and image, and the specific content of micro teaching unit is library on the current teaching. Specially made "small course-ware" completes an important knowledge or difficult knowledge teaching. Integral ware combination terrace is a relatively open software system, and teachers can combine integral ware library and then realize the teaching of different subjects.

\section{B. The characteristics of integral ware platform}

Integral ware platform mainly has features like: no need to do a program design, the integration of the material in the library, and the composition of teaching resources. For teachers, it is easy to learn, and has convenient application. Integral ware platform relates multiple platforms for high quality combination, thus forms a teaching course-ware combination platform, which makes teaching more interesting and visualized.

The core technology integral ware platform uses in the process of combination is object linking and embedding technology, embeds material resources or links in the teaching unit to current teaching content, and at the same time, these embedded or linked data and running environment can be from each other, that is, they can be modified; This makes the difficulty in the process of making teaching course-ware reduced a lot and more personalized. According to the actual teaching content, make corresponding changes which saves the teachers' preparation time. On the other hand, the teacher can choose the relative teaching resources to their teaching from the library, and then through integral ware combination platform, design combination and form teaching course-ware with personal style characteristics.

\section{THE ADVANTAges OF USING INTEgRAL WARE IN PHYSICAL EDUCATION CURRICULUM COURSE-WARE MAKING}

Traditional course-ware is the course-ware being used for a long time, which is more complete, comprehensive, coherent and logical, but such course-ware has strong stability, and has strong limitation on teachers' ability of independent play, which also has certain influence on the quality of teaching.

General course-ware is for a lecture or certain knowledge, so the use of each course-ware is with strong pertinence and is used for a long time. Compared with the actual situation, it has increasing hysteresis. Physical education curriculum is usually more flexible, because there is more action teaching. Compared with other academic subjects, PE is more vivid and active and is more vulnerable to get student's welcome. In the process of making course-ware, if some larger events or high-profile music or songs are introduced into the course-ware, it may rouse the resonance of the students and improve the students' study enthusiasm; teaching method can be from abstract to concrete to make the students understand the teaching content better and faster for better learning [3].

\section{PHYSICAL EDUCATION CURRICULUM INTEGRAL WARE MODEL ANALYSIS}

In teaching process, we need to divide the whole content. According to the characteristics of the teaching content, set up corresponding independent system and structure and form multiple small 
integral wares in order to improve the efficiency of teachers' use of integral ware. Set up physical education curriculum integral ware model on taekwondo, and each small integral ware includes five modules, which is shown in Figure 1.

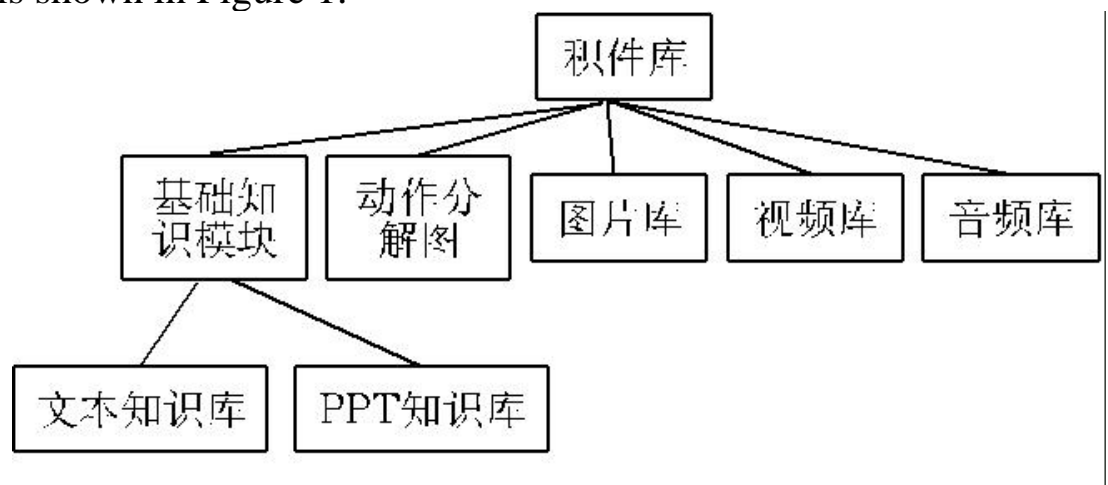

Figure 1 Integral ware model schematic diagram

\section{A. Basic knowledge module}

Under the existing computer technology, the division of basic knowledge module has two kinds: text knowledge library and PPT knowledge library. Text knowledge library mainly is to make the corresponding explanation of each knowledge point, and it has strong independence and is named after knowledge document. It chooses TXT document format. Take taekwondo for example, it is mainly leg movements. Through the teaching of variety movements, the students can give full play to the corresponding power and gradually improve personal ability in the practice so as to help them win in actual combat; Taekwondo lower-middle splitting is the most basic action, and take this action's meaning for example, make "Lower splitting action definition and description. txt" document, which is shown in Figure 2. Choose the format and avoid the fail of open file because of teachers and students using different computer, system and software and increase the generality of integral ware.

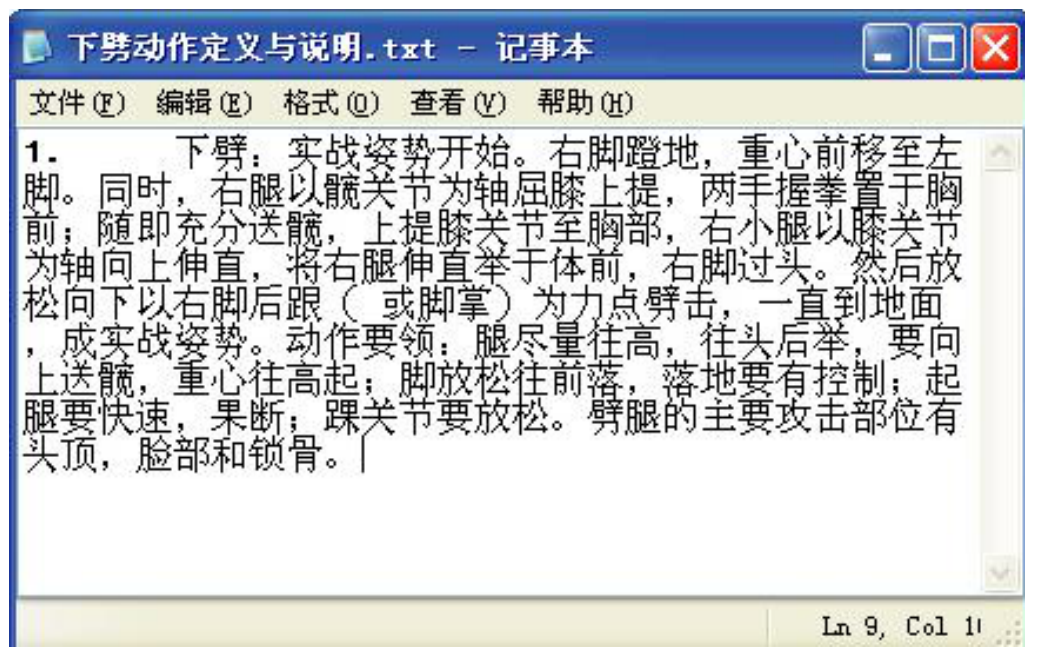

Fig. 2 Lower splitting action explanation file

PPT knowledge library shows the main content of the curriculum in the form of PPT to the students. The show display make students understand the knowledge points directly and vividly.

B. Action diagram

Motion diagram can also be called physical education drawing. Movements are decomposed and then shown in the form of images in teaching, which is helpful for students to have a clearer understanding of the move and grasp the behavioral essentials. Combined with the teacher's explanation, a better teaching goal can be achieved.

Physical drawing pictures taekwondo course related knowledge and motions according to different morphology and structure characteristics of taekwondo movement through the use of drawing method. This form has strong visualization and shows human motion diagram and organization forms for students. Motion diagram is a kind of teaching method which is commonly used in physical education classroom, especially in the process of physical education teaching, 
teachers gush text description for ten minutes and students can hardly get impressed than by a picture. Physical education teachers always use it in making teaching plan, course-ware or doing scientific research.

After the pictures are completed, usually name them after the specific content in order to ensure the picture generality and save format is commonly ".jpg "or" .jpeg ".

\section{Photo gallery}

Pictures in integral ware photo library are usually more classic motion pictures. With the characteristic, they can leave a person deep impression. The existence of picture library can enrich the existing course-ware content and illustration effect will be more beautiful to attract the attention of students.

Pictures in the library are commonly in "jpg" format, and this format can compress the images for smaller capacity. But in the process of compression, duplicate or not important data will be lost.

Jpg format images' compression ratio can be controlled. According to the original size, adjust the appropriate compression rate to preserve and use. Especially for the pictures taken by digital camera with larger volume, the compression rate is smaller.

\section{Video library}

As a collection of teaching resources, each module classification in integral ware library is collected and integrated for better service to the masses of teachers and students. Video library usually stores all kinds of classic video clips or large game highlights of physical education. Because each project has its uniqueness in physical education, video is a more intuitive representation than image.

\section{E. Audio library}

Audio library is also an important module in integral ware, and audio seems of little use in physical education teaching, but it contains some classic physical education music files, which have a very positive impact to mobilize the classroom atmosphere. For instance, add classroom knowledge related music in the course-ware, and when students practice, play it out as background music. This should make a good classroom atmosphere for students and is more conducive to students' action practice.

\section{SOME SUGGESTIONS ON PE INTEGRAL WARE MODEL ESTABLISHMENT}

In the process of establishing integral ware resource, make standardized design and development. This improves the applicability and versatility of integral ware, and promotes integral ware for a wider range of application. The standardization design of integral ware is related to two aspects. One is that the choice of programming language, multimedia system and the selection of operating software have a very important impact on integral ware's final effect; Second is that the material storage type developed and designed is the general type, such as text is usually in text format, and images are in jpg or jpeg format to facilitate teachers in making course-ware, which is more convenient and simple.

There is the need to further strengthen the application of specific skills integral ware combination terrace of physical education in physical education teaching. In the development and design, pay attention to combine with all aspects of subject knowledge, such as psychology and computer technology for integration and complementary to make further improvement of software function realization [4]. After putting into use, make regular tracking and investigation, and according to the teachers' and students' reaction, further improve and modify it. The course composing of integral ware also needs enough material so as to make teachers and students have convenient usage. Thereby, physical education teaching goal, students physical exercise and physical fitness, can be realized.

\section{CONCLUSION}

Integral ware is a collection of teaching materials and teaching methods, which can provide a lot of knowledge information and teaching resources material to teachers and students for free use in 
actual physical education teaching. For physical education course, a lot of information resources are common, such as warm-up act and warm-up exercise, etc. It is a foundation practice of any physical education, and can be applied to different courses repeatedly. And integral ware also has high flexibility and openness, namely, both teachers and students can upload their related resources to integral ware library. This not only makes integral ware library resources richer, and at the same time, greatly promotes teaching and student's physical education knowledge.

With constant improvement of computer level, traditional physical education teaching course-ware is gradually replaced by integral ware. In contrast, integral ware brings greater convenience to teachers and students. This shift is also kind of inevitable. Physical education curriculum itself has a lot of convergence, and with the development of the society, physical education project changes. Rich projects require that integral ware have more powerful information resources for the use of teachers and students. The establishment and use of integral ware also need constant update and perfect in order to better serve mass teachers and students.

\section{REFERENCES}

[1] Zhang Junxing. Physical education classes integral ware model establishment---- take taekwondo for example [J]. Journal of Langfang Normal University (Natural Science Edition), 2014, 02:28-30.

[2] Shan Zhihui. The development and application research of physical education special skills integral ware combination terrace [D]. Shandong Physical Education Institute, 2012.

[3] Zhou Changtao. The three dimensional kinematic characteristics study on men taekwondo high level athletes under splitting technique [J]. Journal of Shandong Physical Education Institute, 2012, (5) : 79-84.

[4] Zhuo Lei. The present teaching situation and development strategy research on free combat specialized elective course teaching in physical education departments of Shandong colleges and universities [J]. Journal of Shandong Physical Education Science and Technology, 2011, (6) : 67-69. 